\title{
The October 1987 Storm: Widespread Damage to Trees in Southern England
}

On the night of the 15-16 October 1987, a deep depression worked its way north-east towards the English Channel, following which its direction veered to a more northerly one from Cornwall to Humberside. Recriminations concerning the alleged lack of warning from the weathermen are of academic importance, as little or nothing could have been done to limit the enormous damage wrought to trees and buildings. It has been said that this was probably the most severe storm to hit the area since 1703 .

The destructive effects of the storm were fairly strictly limited to the area to the south and east of a line joining the Isle of Wight, the Chiltern Hills, and north-east Norfolk. Sussex, Kent, and southern Hampshire, together with parts of London and Surrey, suffered the greatest damage. Whilst there was structural damage on a large scale and many areas suffered a loss of electricity supplies for several days, the more lasting effects of the storm are to be seen throughout the affected region in the devastation of familiar landscapes.

It has been estimated that something like 15 million trees were destroyed in the storm, many areas of woodland being all but flattened. The majority of trees affected were uprooted rather than broken (Figs 1, 2 and 3), the soil evidently providing little anchorage after unusually heavy rainfall earlier in the month. Other trees were snapped off at 5-10 $\mathrm{m}$ above the ground, whilst still others lost a large proportion of their crowns. The effects of tree loss on amenity areas fall into 2 main categories: large wooded public spaces have in many instances been transformed by the destruction of $60-80 \%$ of their mature tree cover, while the 'feel' of such places has been altered for perhaps 50 years-until the necessary replanting becomes established and reasonably mature.

Several well-known gardens suffered in another way, namely by the loss of innumerable fine specimen trees and examples of rare species. Gardens such as Kew, Wakehurst Place, Sheffield Park, Nymans, and Winkworth Arboretum, are now having to plan replanting on a scale which they could never have envisaged. Nearer home for the writer, the Royal Horticultural Society's (RHS) Garden at Wisley, Surrey, was on the edge of the worst-affected area and escaped relatively lightly. Here, probably around 500 trees were destroyed within the garden. However, the great majority of these were mature or over-mature trees in the canopy of native oaks (Quercus spp.), Scots Pine (Pinus sylvestris), and Sweet Chestnut (Castanea sativa). It seems

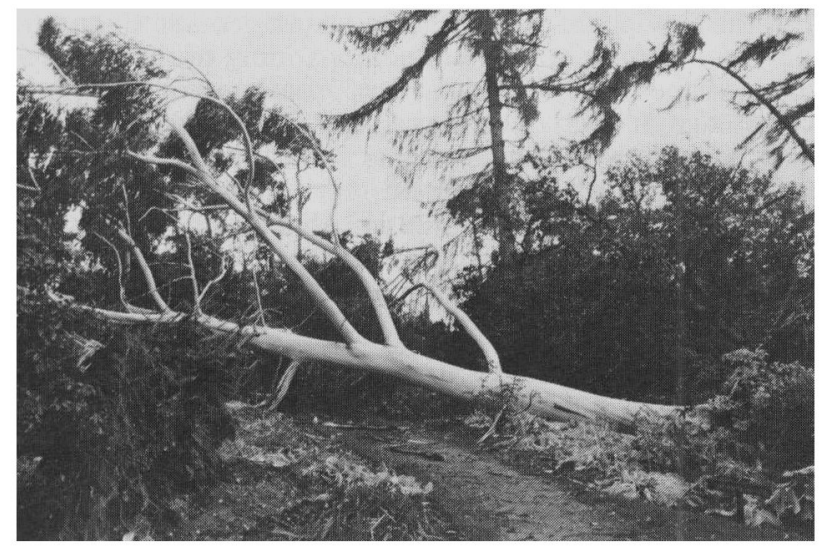

FIG. 1. Scots Pines (Pinus sylvestris) uprooted on the top of Battleston Hill, Wisley, prostrate after the storm.

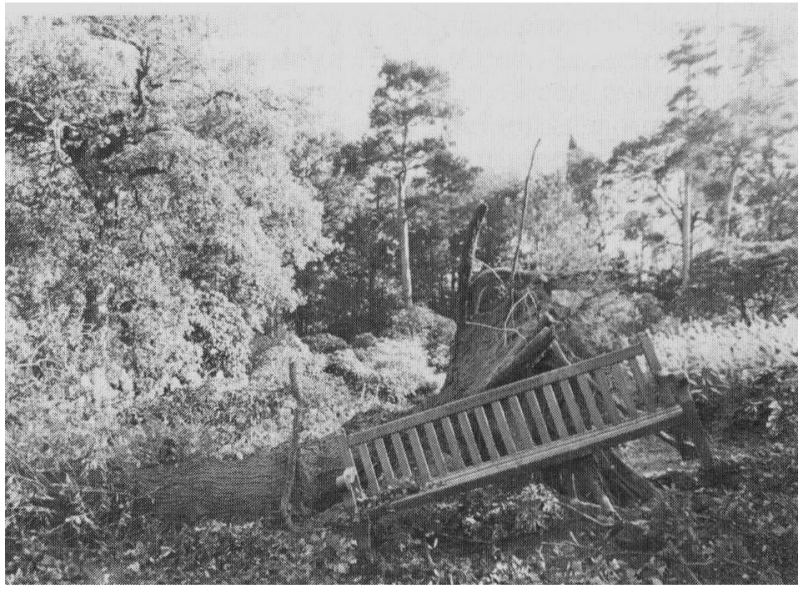

Fig. 2. Common Oak (Quercus robur) on Battleston Hill, Wisley: which had been uprooted, by the storm.

likely that there will be further losses as the damage to root systems and crowns of other trees takes its toll. The number of intrinsically valuable trees lost in the RHS Garden at Wisley, is probably less than 100 and may be as few as 50 . In the older, wooded parts of the Garden, however, there will inevitably be long-term effects arising from the loss to the under-plantings of shade and shelter.

The damage sustained by trees in this storm was clearly compounded by two factors. First, as has been mentioned already, the gales were preceded by a period of unusually high rainfall which rendered root systems insecure. Secondly, the direction of the winds, which were predominantly southerly at the height of the storm, was somewhat unusual, and it seems likely that, had the winds been from the more normal westerly quarter, the damage might have been less. In this connection it is interesting to note that a substantial amount of the damage to such foliage as remained after the storm, resulted from salt carried on the wind-even in gardens rather many miles inland.

Quite by chance, several references to another severe October storm were found in the Gardener's Chronicle. This was on 13 October 1881 , and the occurrence of two

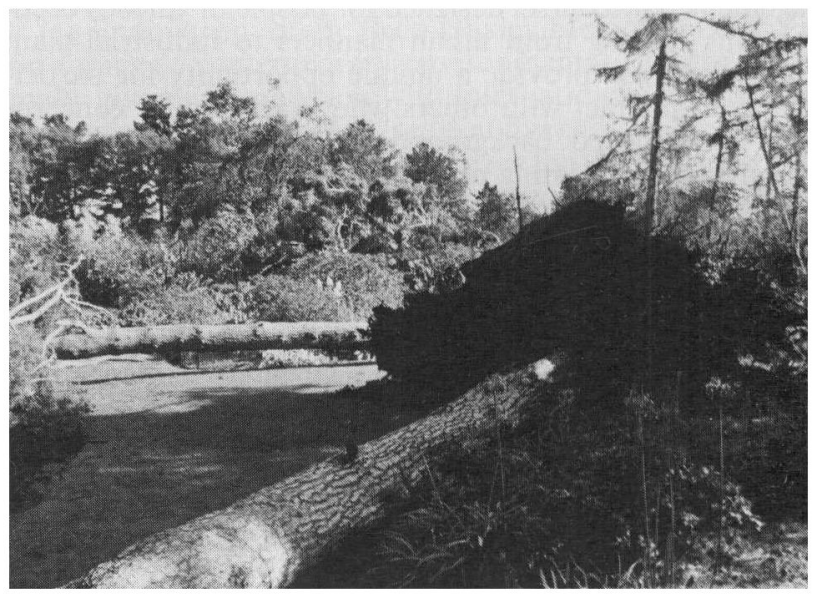

FIG. 3. An exotic, Eucalyptus dalrympleana, which had stood $21 \mathrm{~m}$ high, uprooted by the storm at Wisley. 
such storms at the same time of year invites comparisons. The similarities lie not only in the season but in the scale of damage to parks and gardens, with estimates of tree loss as high as 1,000 in some estates. The major difference is that the 1881 storm spread its effects over a much wider area, with severe damage reported from London, Warwickshire, Norfolk, and south-east Scotland.

It is very difficult at this stage to learn any lessons from the recent storm, other than the need to be philosophical about such natural phenomena. It is doubtful whether the increased planting of shelter-belts, for example, is justified, as it was noticeable that some of the most severe destruction occurred within apparently sheltered woodland areas. Certainly at Wisley, plantings in the new arboretum, less than 10 years old and on a slope that was completely open to the south, suffered much less than did areas of more or less mature woodland, both within and outside the Garden.

As to the future, it is to be hoped that the positive aspects of such an event can be exploited to the full. There are clearly greater opportunities for replanting in many wellestablished gardens than there have been for very many years. It is to be hoped that this task will not be rushed into headlong; for it is the plantings that are carried out over the next few years that will, storms permitting, form the landscapes of future centuries.

PETER G. BARNES, Botanist
Royal Horticultural Society's Garden
Wisley
Woking
Surrey GU23 $6 Q B$
England, UK.

\section{Towards a University of the Mediterranean?}

In May 1983 a Conference on Scientific Cooperation among the Universities of the Mediterranean Sea was held in Bari, Italy, in order to assess the possibilities for their cooperation in scientific and humanistic research. The choice of the University of Bari for this Conference revives a centuries-old tradition which has made Bari and environs a focal region of contact between the different areas of the Mediterranean. A commitment involving scientific and cultural cooperation among the Universities of the Mediterranean Sea, each with its own particular cultural history, was considered to be the most suitable means of rediscovering the roots which are common to the peoples and cultures of the Mediterranean. The historical background of the civilization and peoples of the Mediterranean as presented by Fernand Braudel encouraged this hope. The "cultural pollen' which had circulated through the centuries in the Mediterranean area, carried by sailors, merchants, pilgrims, pirates, and warriors, and which has created a subtle framework of links, was thereby to result in unified activity among the universities and scholars in our particular region.

The response from the participants of the Conference was very encouraging; the interesting subjects dealt with by the six working groups resulted in the final motion which was unanimously approved. However, three central and closely-connected problems emerged, for which the Universities of the Mediterranean would have to develop common programmes of research. They are: (1) the exploitation of natural and environmental resources, (2) the exploitation of scientific potential to overcome technological imbalance, and (3) the exploitation of cultural and artistic values.

\section{Permanent Commission Established}

In order to achieve these programmes, the Conference decided to set up a Permanent Commission, delegating the University of Bari to promote the necessary contacts with the other universities for a future meeting. This meeting was held in Bari in September 1983, during which the Community of Mediterranean Universities was constituted and its statute approved. This statute is composed of 13 articles and a number of temporary rules, the first of which states the objectives of the Community of Mediterranean Universities as:

1) to reaffirm and develop the role and function of culture and technological and scientific research for the resolution of the difficult and complex problems created by the development of the countries of the Mediterranean sea;
2) to promote scientific cooperation among the Mediterranean universities, using the experience and resources of each university while respecting the differences and the specificity of the different nationalities; and

3) to set up permanent links among the abovementioned universities through the reciprocal exchange of scientific and cultural experience and information of teaching staff and students.

In the other articles, the duties and functions of the various sections of the Community are specified: they are the President, the General Assembly of the Member Universities, the Council of the Community, the Head Office, and the permanent Work Commissions.

In Art. 8, four commissions were designated first in order to carry out the activities of the community:

1) Commission for Educational and General Affairs.

2) Commission for Cultural Affairs.

3) Commission for Scientific Affairs.

4) Commission for Communication Affairs.

The statute, in its essential form, has three key ideas: a) to involve the representatives of the different national groups as much as possible; b) to stimulate genuine cooperation whose ultimate point of reference-besides, naturally, the progress of science-should be the improvement of relations among the peoples of the Mediterranean; c) furthermore to cover all fields of scientific research and to compare the different experiences and methodologies which have developed in the Mediterranean Universities.

\section{Assemblies of the Community}

In the first assembly of the Community of Mediterranean Universities, held in Bari in May 1984, the regulations establishing the functioning of the various sections of the Community were approved - in particular a secretarial staff was set up for the Head Office, the structure of the Work Commissions was defined, the procedures for the presentation and the evaluation and financing of the research projects were specified, and the publication of a Community Bulletin was decided upon. With regard to the regulations, I should stress the meaning of the rule requesting that projects be presented by at least three different countries of the Mediterranean; this expresses the spirit of cooperation required by the Community and points out the ways in which cooperation must develop. After the approval of the regulations, the Council of the Community was established and the Presidents of the Work Commissions were appointed. 